\title{
Myocardial Kinetics of Thallium-201 after Dipyridamole Infusion in Normal Canine Myocardium and in Myocardium Distal to a Stenosis
}

\author{
Robert D. Okada, Jeffrey A. Leppo, Charles A. Boucher, and Gerald M. Pohost, \\ Cardiac Unit, Department of Medicine of the Massachusetts General \\ Hospital, Harvard Medical School, Boston, Massachusetts 02114
}

A в STRACT The purpose of the present study was to define myocardial and blood thallium-201 (Tl-201) kinetics after infusion of dipyridamole in normal canine myocardium and in myocardium distal to a coronary artery stenosis. Miniature radiation detector probes were implanted in the left ventricle in 39 openchest dogs. A balloon constrictor was placed around the proximal left circumflex coronary artery. Electromagnetic flow probes were positioned proximally around both the left circumflex and left anterior descending coronary arteries. In five control dogs (group 1) the balloon occluder was not inflated; in 12 dogs (group 2) a mild stenosis was created such that resting flow was not reduced, yet the hyperemic response after $10 \mathrm{~s}$ of total occlusion was partially attenuated; in nine dogs (group 3) a moderate stenosis was created such that resting flow was not reduced, yet the hyperemic response was completely eliminated; and in 13 dogs (group 4) a severe stenosis was created such that resting flow was reduced. After intravenous dipyridamole $\left(0.08 \mathrm{mg} / \mathrm{kg} \cdot \mathrm{min}^{-1} \times 4 \mathrm{~min}\right), 1.5 \mathrm{mCi} \mathrm{Tl}-201$ was injected intravenously and probe counts were collected continuously for $4 \mathrm{~h}$. The mean 4 -h fractional myocardial Tl-201 clearance for nonstenotic zones was $0.35,0.27$ for group 2 stenotic zones, 0.19 for group 3 stenotic zones, and 0.05 for group 4 stenotic zones $(P<0.0001)$. After reaching peak activity, myocardial Tl-201 activity cleared biexponentially with a final decay constant $\lambda_{2}=0.0017 \pm 0.0001 \mathrm{~min}^{-1}$ (SE) for nonstenotic zones, $0.0011 \pm 0.0001 \mathrm{~min}^{-1}$ for group 2 stenotic zones, and $0.0006 \pm 0.0001 \mathrm{~min}^{-1}$ for group 3 stenotic zones $(P<0.01)$. Group 4 stenotic zone $\mathrm{Tl}-$ 201 clearances were negligible (decay constant essen-

Dr. Pohost is an Established Investigator of the American Heart Association. Address reprint requests to Dr. Okada, Massachusetts General Hospital.

Received for publication 6 May 1981 and in revised form 24 July 1981. tially zero). Blood Tl-201 activity decayed triexponentially with a final blood $\lambda_{3}=0.0018 \pm 0.0001 \mathrm{~min}^{-1}$, which was almost identical to the final myocardial $\lambda_{2}$ decay constant.

Thus, the rate of myocardial Tl-201 clearance can distinguish between coronary stenoses of graded hemodynamic severity. These results may be applicable to quantitative techniques for determining myocardial Tl-201 clearance rates on serial clinical images after dipyridamole administration.

\section{INTRODUCTION}

Clinical imaging with thallium-201 (Tl-201) in conjunction with exercise stress is used with increasing frequency for the diagnosis of coronary artery disease (1). Partial or total disappearance of an initial postexercise Tl-201 image defect over time (Tl-201 redistribution) suggests transient ischemia $(2,3)$. Investigators have also attempted to detect abnormally perfused myocardium by determining the myocardial clearance rates from serial Tl-201 images (4-7).

Gould and associates have described Tl-201 imaging after an intravenous infusion of dipyridamole, a potent vasodilator (8-10). The technique was developed in an effort to improve the diagnostic accuracy of Tl-201 imaging in patients unable to exercise. Tl-201 redistribution was subsequently observed on serial clinical Tl-201 images after dipyridamole (11). Accordingly, the purposes of the present study with dipyridamole and a canine model were $(a)$ to define myocardial and blood Tl-201 clearance kinetics after dipyridamole, (b) to quantitate myocardial Tl-201 clearance rates after dipyridamole distal to either nonstenotic or progressively stenotic coronary arteries, $(c)$ to determine the time-course and mechanism of Tl-201 heterogeneity resolution after dipyridamole, and $(d)$ to define the hemodynamic consequences of a dipyridamole infusion. 


\section{METHODS}

39 adult mongrel dogs (mean weight, $21 \mathrm{~kg}$; range, 18-23 $\mathrm{kg}$ ) were anesthetized with chloralose $(140 \mathrm{mg} / \mathrm{kg} \mathrm{i.v.)}$ and urethane $(1,400 \mathrm{mg} / \mathrm{kg}$ i.v.). The dogs were intubated and placed on a respirator (Harvard Apparatus, South Natick Mass.) with $5 \mathrm{~cm}$ of positive end-expiratory pressure and $100 \%$ oxygen. The heart was exposed via a left thoracotomy and suspended in a pericardial cradle. A $20-\mathrm{cm}$ vinyl catheter was inserted into the right atrium for dipyridamole and Tl-201 administration. A second vinyl catheter was inserted into the left atrium for monitoring left atrial pressure and for injecting microspheres for regional myocardial blood flow determinations. A No. 7 National Institutes of Health catheter was placed in the brachial artery and positioned in the aortic arch to monitor aortic pressure and to obtain specimens of blood for determination of arterial $\mathrm{pH}, \mathrm{PCO}_{2}, \mathrm{Po}_{2}$, and microsphere reference samples. A No. 7 Swan-Ganz catheter was positioned in the pulmonary artery for thermodilution cardiac output determinations. The proximal left circumflex coronary artery was dissected free and an inflatable balloon occluder was positioned but not inflated. A small vinyl catheter was placed retrograde into a distal branch of the left circumflex coronary artery for pressure monitoring distal to the balloon occluder. Electromagnetic flow probes were positioned around the proximal left anterior descending coronary artery and around the left circumflex coronary artery just proximal to the occluder.

Electrocardiographic lead II, pressures (P23Db transducers, Gould Inc., Oxnard, Calif.), and electromagnetic flow probe-determined coronary artery blood flow were monitored continuously throughout the experiment and recorded on paper with a Hewlett-Packard Co. (Palo Alto, Calif.) recorder (model $7788 \mathrm{~A}$ ). Cardiac output was determined every minute during the dipyridamole infusion and every 15 min during the remainder of the experiment. Specimens of arterial blood were obtained at frequent intervals to assess $\mathrm{pH}, \mathrm{PO}_{2}$, and $\mathrm{PCO}_{2}$. Appropriate adjustments were made to maintain these parameters in the physiologic range (pH 7.35-7.45 and $\mathrm{PCO}_{2} 30-40 \mathrm{~mm} \mathrm{Hg}$ ). Arterial $\mathrm{PO}_{2}$ was maintained between 100 and $150 \mathrm{~mm} \mathrm{Hg}$ throughout the experiment.

A miniature cadmium telluride radiation detector attached to a modified arterial clamp was inserted through the left ventricular apex, positioned against the posterior wall endocardium, and used for on-line monitoring of Tl-201 activity distal to the balloon occluder (Fig. 1). A similar detector was positioned against the left ventricular anterior wall endocardium. The endocardial position for the detectors was chosen so that monitored activity would be uncontaminated by activity from the opposite wall and the blood pool. The anterior wall detector was positioned to face through the open thoracotomy, thus further reducing background activity. A lead sheet (1/8 in.) was placed between the posterior wall and the pericardium to further reduce background activity from this probe. The physical characteristics of the cadmium telluride probes have been reported (12). Each probe had 1-mm thick lead back and side shielding. The probes were connected via preamplifiers to a multichannel analyzer (series 30, Canberra Industries, Meriden, Conn.), which allowed continuous monitoring and display of Tl-201 activity in the two regions. Radiation data were continuously recorded on paper tape and magnetic tape as counts per minute. The data (counts per minute vs. time) were also displayed on the multichannel analyzer cathode ray display and photographed on Polaroid film (Polaroid Corp., Cambridge, Mass.). Sonomicrometer transducer crys- tals (3 mm Diam) were attached to both arms of each arterial clamp and connected to a sonomicrometer (model NI-2024R, Norland Instruments, Fort Atkinson, Wis.). Wall thickness was continuously monitored to correct for radioactivity resulting from changes in wall thickness (13).

Fig. 2 demonstrates the experimental protocol. Base-line steady-state hemodynamic measurements were recorded. The maximal hyperemic response of the blood flow through each coronary artery was assessed by occluding each coronary artery proximally with a hemostat for $10 \mathrm{~s}$, releasing the occlusion, then observing the hyperemic response as determined by the electromagnetic flow probes. In five control dogs (group 1) the balloon occluder was not inflated. In 12 dogs (group 2) a mild left circumflex coronary artery stenosis was created such that resting flow was not reduced, yet the hyperemic response after $10 \mathrm{~s}$ of total occlusion was only partially attenuated. In nine dogs (group 3) a more severe left circumflex coronary artery stenosis was created such that resting flow was not reduced, yet the hyperemic response was abolished. In 13 dogs (group 4) a severe left circumflex coronary artery stenosis was created such that resting flow was reduced and there was no hyperemic response. After a 30-min period that allowed stabilization of the hemodynamic parameters, regional myocardial blood flow was then determined by the administration of $\sim 4.5$ million ruthenium-103-labeled 8- to $10-\mu \mathrm{m}$ microspheres $(30 \mu \mathrm{Ci}$ total activity) into the left atrium (New England Nuclear Corp., North Billerica, Mass.). Arterial reference blood samples were collected for $2 \mathrm{~min}$ after injection of the microspheres. An intravenous infusion of dipyridamole $(0.08 \mathrm{mg} / \mathrm{kg}$. $\mathrm{min}^{-1}$ ) (Boehringer Ingelheim Ltd., Ridgefield, Conn.) was then started and continued for 4 min using a constant infusion pump. Hemodynamic parameters were recorded during and after the infusion. 2 min after termination of the dipyridamole infusion, Tl-201 $(1.5 \mathrm{mCi})$ was injected intravenously and tin-113-labeled microspheres were injected simultaneously into the left atrium. The timing of the dipyridamole infusion and the Tl-201 injection were chosen to approximate that currently used in clinical studies (10). The total number, mean size, and total radioactivity of the Sn113 microspheres were approximately the same as for the Ru-103 microsphere injection. Probe counts were collected continuously in 60-s intervals for both the anterior and posterior left ventricular walls over the following $4 \mathrm{~h}$. Proberecorded Tl-201 activity was at least $5,000 \mathrm{cpm}$ for the stenotic zone and at least $10,000 \mathrm{cpm}$ for the nonstenotic zone for all dogs. To measure blood Tl-201 activity over time, 1$\mathrm{ml}$ arterial blood samples were collected at $2,4,6,8,10,20$, $30,60,90,120,180$, and $240 \mathrm{~min}$ after Tl-201 injection. Just before the dogs were killed, scandium-46-labeled microspheres were injected into the left atrium. The total number, mean size, and total radioactivity of the Sc-46 microspheres were approximately the same as for the Ru-103 and Sn-113 microsphere injections.

$4 \mathrm{~h}$ after Tl-201 injection, the heart was removed, and the areas of myocardium under the probes were subdivided into a total of 48 inner, middle, and outer segments (0.8-1.2 g/ segment). The myocardial and blood microsphere reference samples were counted after Tl-201 activity had decayed 12 half-lives. Serial blood samples were counted for Tl-201 activity within $12 \mathrm{~h}$ of collection. All samples were counted in a well counter (Auto-Gamma Scintillation Spectrometer, Hewlett-Packard Co., Lexington, Mass.) for $5 \mathrm{~min}$ to collect at least 10,000 counts for each isotope. The Tl-201 was counted within a 60-120 keV window, the Sn-113 within a $350-435 \mathrm{keV}$ window, the Ru-103 within a 440-600-keV window, and the Sc-46 within a $800-1,200-\mathrm{keV}$ window. A 


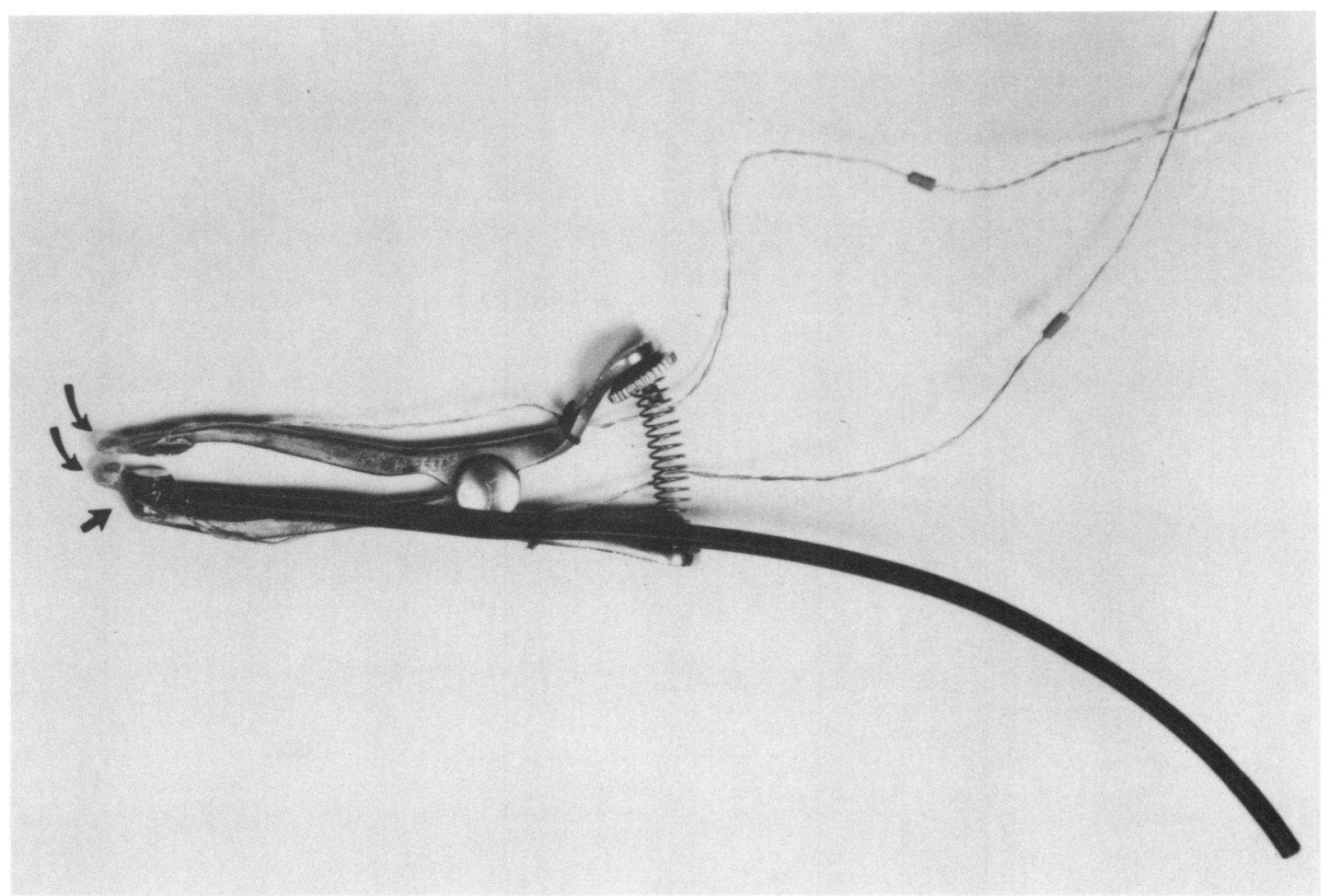

Figure 1 Miniature radiation detector assembly. Straight arrow points to cadmium telluride crystal. Curved arrows point to sonomicrometer crystals.

computer program was used to correct for activity spilling from one window into another. Regional myocardial blood flow was computer-calculated (Digital Equipment Corp. Vax, 11:780, Waltham, Mass.) from the sample activity and the activity in the reference blood samples obtained simultaneously with the administration of each isotope (14). Myocardial blood flow was expressed as milliliters per minute per gram of tissue and as a flow ratio of the left circumflex coronary artery zone (occluder zone) divided by the left anterior descending coronary artery zone (no occluder zone).

Analysis of data: myocardial and blood kinetics of thallium-201 after dipyridamole. The myocardial Tl-201 clearance rate over $4 \mathrm{~h}$ was expressed as the fractional change in probe-determined activity from 1 to 240 min compared with the initial activity. The total myocardial clearance of the isotope was assessed, i.e., biological clearance plus physical decay. Myocardial and arterial blood time-activity curves

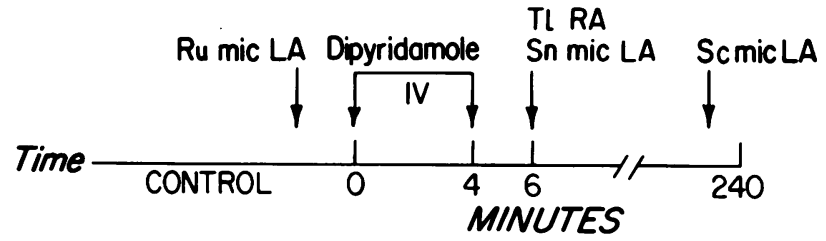

Figure 2 Experimental protocol for the 39 dogs. $R u$ mic $L A$, ruthenium microspheres into left atrium; $I V$, intravenous; $T l R A$, thallium-201 into right atrium; $S n$ mic $L A$, tin microspheres into left atrium; Sc mic $L A$, scandium microspheres into left atrium. were also analyzed with a computer-derived nonlinear leastsquares estimation of the decay constants $\left(\lambda \mathrm{min}^{-1}\right) .^{1}$ The time to peak myocardial Tl-201 activity was defined as the time from $\mathrm{Tl}-201$ injection to the time of maximal probedetermined activity.

Analysis of data: time-course and mechanism of thallium-201 heterogeneity resolution after dipyridamole. Because the myocardial probes had different intrinsic sensitivities, the Tl-20l activity ratio for the two zones at the time the dogs were killed as determined by well-counting was used to correct for the differences in sensitivity. The corrected probe activities were then used to calculate the ratio of activity in the left circumflex coronary artery zone (occluder) divided by activity in the left anterior descending coronary artery zone (no occluder) at 10,60,120,180, and 240 min after Tl-201 administration.

Statistical methods. All results are expressed as mean \pm 1 SEM. Differences between groups of dogs were analyzed by a one-way analysis of variance and the Newman-Keuls multiple-comparison test. Differences between the stenotic and nonstenotic myocardial zones for each group of dogs were analyzed by a paired $t$ test.

\section{RESULTS}

Hemodynamic response to intravenous dipyridamole. Table I lists the hemodynamic measurements

\footnotetext{
${ }^{1}$ Abbreviation used in this paper: $\lambda$, exponential decay constant.
} 


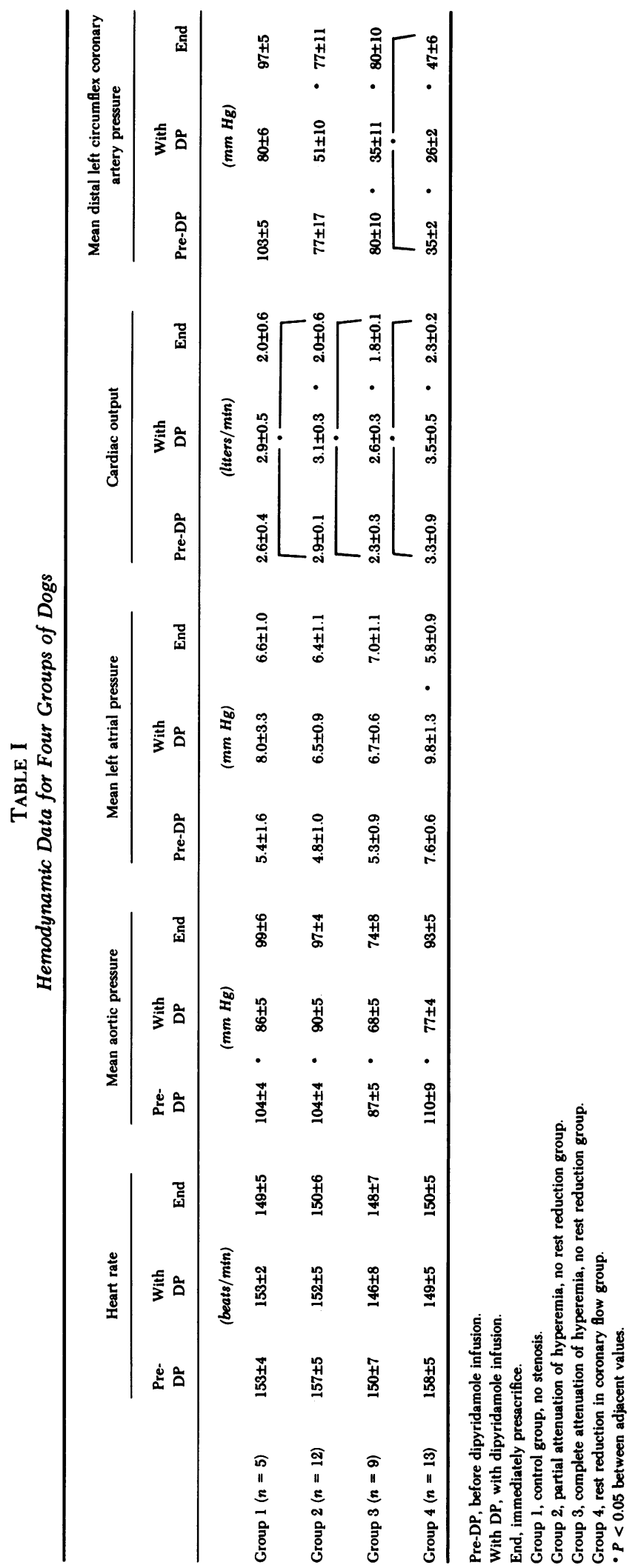


for the four groups of dogs. Mean heart rate did not significantly differ from the predipyridamole value during dipyridamole or at the end of the experiment in any group. Mean aortic blood pressure fell during dipyridamole $(P<0.05$ for groups 3 and 4 ) but returned to near predipyridamole values by the end of the experiment in all the groups. Mean left atrial pressure and cardiac output increased during dipyridamole, but not significantly in any group. Cardiac output, however, was significantly depressed at the end of the experiment compared with predipyridamole and dipyridamole values for all but the control group of dogs $(P<0.05)$. Mean left circumflex coronary artery pressure distal to the stenosis fell significantly during dipyridamole in group 3 and group 4 dogs $(P$ $<0.05$ ).

Sonomicrometer-determined systolic and diastolic wall thicknesses did not change significantly during dipyridamole infusion or during the course of the experiment for the left venticular anterior and posterior walls monitored for radioactivity.

Table II lists the microsphere-determined regional myocardial blood flows for the four groups of dogs. For the group 1 control dogs, there was no significant difference in flow to the left circumflex and left anterior descending coronary artery zones. Myocardial blood flow increased equally and significantly in both zones during dipyridamole ( $83 \%$ over base-line value, $P<0.001)$. For group 2 dogs, although predipyridamole flows were equal and although myocardial blood flow increased throughout the myocardium during dipyridamole $(P<0.001)$, there was partial attenuation of the response to dipyridamole in the stenotic zone $(51 \%$ increase in stenotic zone flow with dipyridamole) $(P<0.01$ comparing stenotic with nonstenotic zone flow during dipyridamole). For group 3 dogs, although predipyridamole flows were equal, there was complete attenuation of the hyperemic response to dipyridamole in the stenotic zone. In fact, stenotic zone flow decreased $25 \%$ during dipyridamole $(P$ $<0.05$ ). In group 4 dogs, stenotic zone flow was reduced predipyridamole $(P<0.01)$ and decreased slightly (18\%), but not significantly, during the dipyridamole infusion.

Fig. 3 demonstrates the myocardial blood flow ratios [left circumflex (stenosis):left anterior descending (no stenosis)] before, during, and $4 \mathrm{~h}$ after dipyridamole. Flow ratios during dipyridamole were significantly depressed compared with predipyridamole and 4-h values for groups 2,3 , and $4(P<0.001)$. There was a progressive fall in the flow ratio during dipyridamole progressing from group 1 through group $4(P<0.001)$.

Myocardial and blood kinetics of thallium-201 after dipyridamole. Fig. 4 demonstrates representative myocardial Tl-201 time-activity curves photographed from the multichannel analyzer display for the four groups of dogs.

Table III lists the Tl-201 myocardial and blood clearance data for the four groups of dogs. There was no significant difference in the 4-h fractional myo-

TABLE II

Microsphere-determined Regional Myocardial Blood Flow for Four Groups of Dogs

\begin{tabular}{|c|c|c|c|c|c|c|c|}
\hline & \multicolumn{2}{|c|}{ Pre-DP } & \multicolumn{2}{|c|}{ With DP } & \multicolumn{3}{|c|}{ End } \\
\hline & Stenosis & No stenosis & Stenosis & No stenosis & Stenosis & & No stenosis \\
\hline & \multicolumn{7}{|c|}{$\mathrm{ml} / \mathrm{min} \cdot \mathrm{g}^{-1}$} \\
\hline Group $1(n=5)$ (LCx control zone) & 一 & $1.39 \pm 0.12$ & - & $2.54 \pm 0.59$ & - & & $1.03 \pm 0.17$ \\
\hline Group $1(n=5)$ (LAD control zone) & - & $1.35 \pm 0.09$ & - & $2.54 \pm 0.47$ & - & & $0.93 \pm 0.14$ \\
\hline Group $2(n=12)$ & $1.34 \pm 0.16$ & $1.32 \pm 0.14$ & $2.02 \pm 0.11$ & - $\quad 3.20 \pm 0.17$ & $1.09 \pm 0.14$ & & $1.15 \pm 0.16$ \\
\hline Group $3(n=9)$ & $1.30 \pm 0.22$ & $1.24 \pm 0.19$ & $0.97 \pm 0.15$ & - $\quad 2.08 \pm 0.26$ & $0.76 \pm 0.11$ & & $0.83 \pm 0.13$ \\
\hline Group $4(n=13)$ & $0.50 \pm 0.09 \ddagger$ & $1.22 \pm 0.16$ & $0.41 \pm 0.07$ & - $\quad 2.81 \pm 0.47$ & $0.45 \pm 0.08$ & - & $0.90 \pm 0.09$ \\
\hline
\end{tabular}

Pre-DP, before dipyridamole infusion.

With DP, with dipyridamole infusion.

End, immediately presacrifice.

Group 1, control group, no stenosis.

Group 2, partial attenuation of hyperemia, no rest reduction group.

Group 3, complete attenuation of hyperemia, no rest reduction group.

Group 4, rest reduction in coronary flow group.

LCx, left circumflex coronary artery.

LAD, left anterior descending coronary artery.

- $P<0.01$ between adjacent values.

f $P<0.01$ compared with all other Pre-DP values.

See text for comparisons between times. 


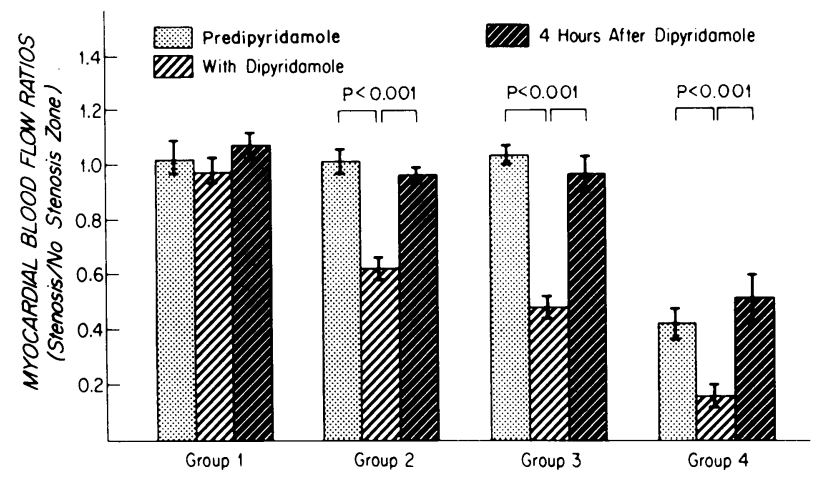

Figure 3 Microsphere-determined regional myocardial blood flow ratios (stenosis:no stenosis zones) before, during and $4 \mathrm{~h}$ after dipyridamole infusion. Group 1, control group, no stenosis. Group 2, partial attenuation of hyperemia group. Group 3, complete attenuation of hyperemia group. Group 4 , rest reduction in coronary flow group.

cardial Tl-201 clearance for any of the nonstenotic zones. The mean 4-h fractional myocardial $\mathrm{Tl}-201$ clearance for all nonstenotic zones was $0.350 \pm 0.014$. There was a progressive reduction in the 4 -h fractional myocardial Tl-201 clearance for the left circumflex coronary artery zone (balloon occluder) from group 1 through group 4 values $(P<0.0001)$ (Fig. 5). There was no significant difference in the time to peak myocardial Tl-201 activity for any of the nonstenotic zones. The mean time to peak myocardial Tl-201 activity for all nonstenotic zones was $4.8 \pm 0.8 \mathrm{~min}$. There was a progressive increase in the time to peak myocardial Tl-201 activity for the left circumflex coronary artery zones (balloon occluder) from group 1 through group 4 values $(P<0.001)$.

After reaching peak activity, myocardial Tl-201 activity cleared biexponentially from the nonstenotic zones (Table III). The first decay constant $\lambda_{1}$ was $0.0611 \pm 0.0080 / \mathrm{min}$, followed by a second decay constant $\lambda_{2}=0.0017 \pm 0.0001 / \mathrm{min}$. The second exponential $\left(\lambda_{2}\right)$ began $20 \pm 5 \mathrm{~min}$ after Tl-201 was injected. There was no significant difference in the nonstenotic zone values for $\lambda_{1}$ or $\lambda_{2}$ for the four groups of dogs. After reaching peak activity, myocardial Tl-20l activity cleared biexponentially from the stenotic zones of groups 2 and 3 dogs. Stenotic zone $\lambda_{1}$ decay constants were smaller than nonstenotic zone $\lambda_{1}$ decay constants, but the differences were not significant. However, there was a progressive reduction in the $\lambda_{2}$ decay constants for left circumflex coronary artery zones (distal to balloon occluder) for group 1 through group $3 \operatorname{dogs}(P<0.01)$. The 4 -h myocardial clearance of $\mathrm{Tl}$-201 from the stenosis zone in group 4 dogs was negligible (decay constant essentially zero).

Table III also lists the blood Tl-201 decay constants for the four groups of dogs. Blood Tl-201 activity de- cayed triexponentially. There was no significant difference in the values for $\lambda_{1}, \lambda_{2}$, or $\lambda_{3}$ for the four groups of dogs. Mean blood $\lambda$ values were $\lambda_{1}=$ $0.8636 \pm 0.1482 \mathrm{~min}^{-1}, \lambda_{2}=0.0944 \pm 0.0103 \mathrm{~min}^{-1}$, and $\lambda_{3}=0.0018 \pm 0.0001 \mathrm{~min}^{-1}$. The blood $\lambda_{2}$ exponential began at $9.8 \pm 0.9 \mathrm{~min}$, and the blood $\lambda_{3}$ at $45.0 \pm 7.1$ min after Tl-201 injection. The final blood decay constants $\lambda_{3}$ were not significantly different from the final myocardial decay constants $\lambda_{2}$.

Time-course and mechanism of thallium-201 heterogeneity resolution after dipyridamole. Fig. 6 demonstrates the average myocardial Tl-201 clearance

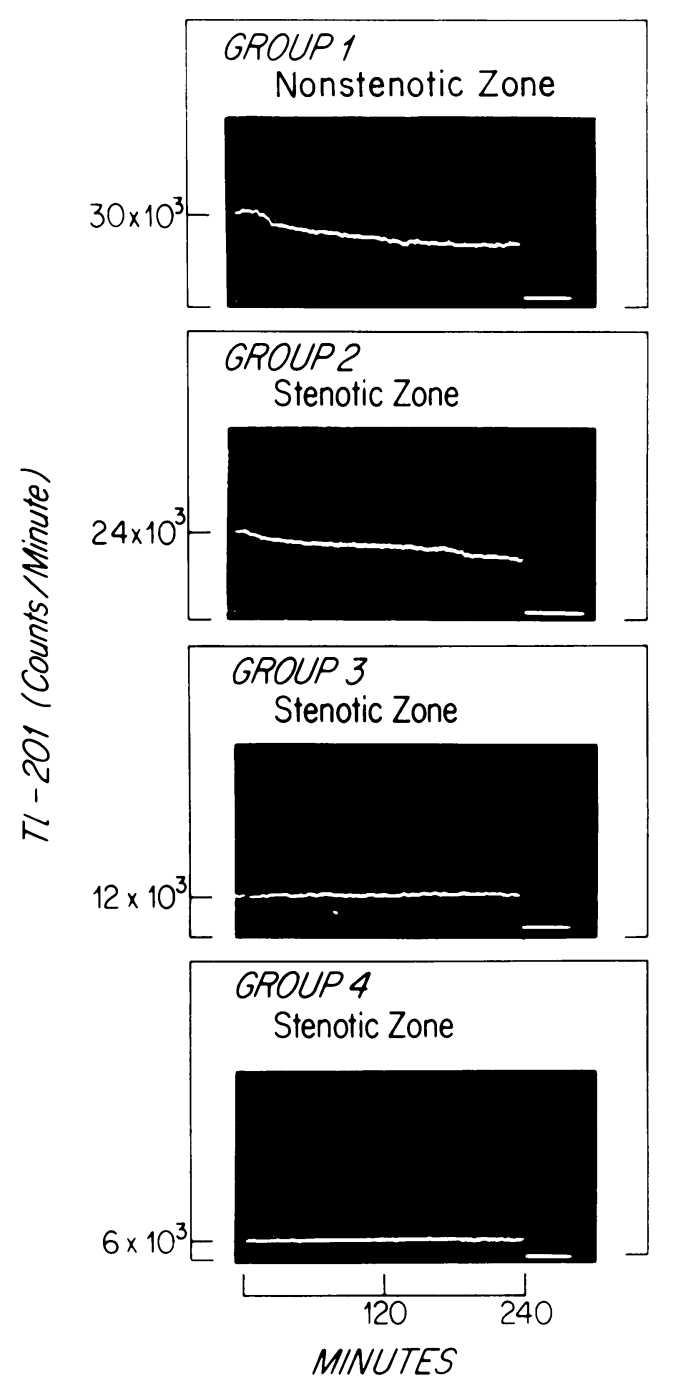

Figure 4 Representative probe-determined myocardial Tl201 clearance curves after dipyridamole infusion photographed from multichannel analyzer display. Group 1, control group, no stenosis. Group 2, partial attenuation of hyperemia, no rest reduction group. Group 3 , complete attenuation of hyperemia, no rest reduction group. Group 4 , rest reduction in coronary flow group. 


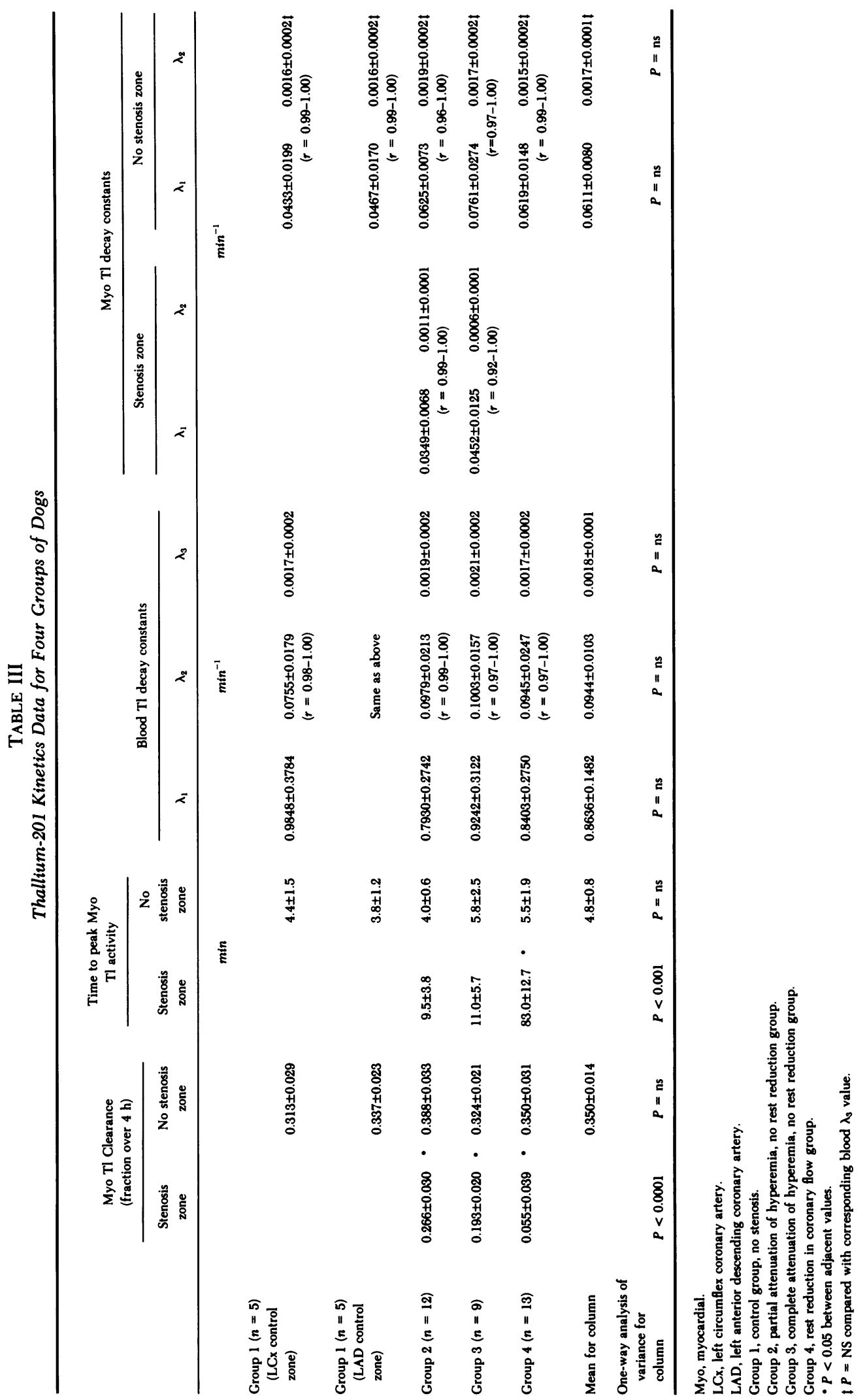




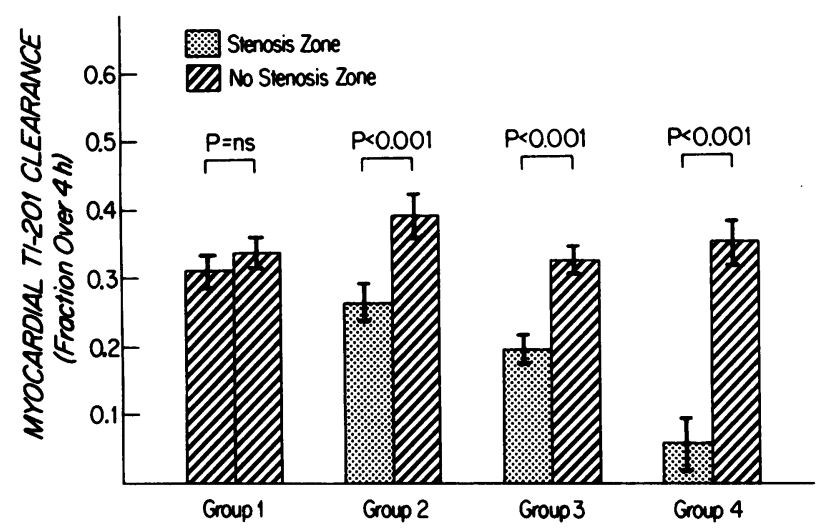

FIGURE 5 Myocardial thallium-201 clearance (fraction over $4 \mathrm{~h}$ ) in the stenotic and nonstenotic zones. Group 1, control group, no stenosis. Group 2, partial attenuation of hyperemia, no rest reduction group. Group 3, complete attenuation of hyperemia, no rest reduction group. Group 4, rest reduction in coronary flow group.

curves for the four groups of dogs. The initial disparity in Tl-201 activity between the nonstenosis and stenosis zones decreased over time by faster clearance of the tracer from the nonstenosis zone compared with the stenosis zone. Fig. 7 demonstrates the myocardial Tl201 activity ratio (stenosis:no stenosis zone) over time for the four groups. For groups 2, 3, and 4, there was a progressive and significant increase in this ratio over the 4-h period.

\section{DISCUSSION}

Quantitative computer techniques for detecting heterogeneities in Tl-20l distribution have been proposed

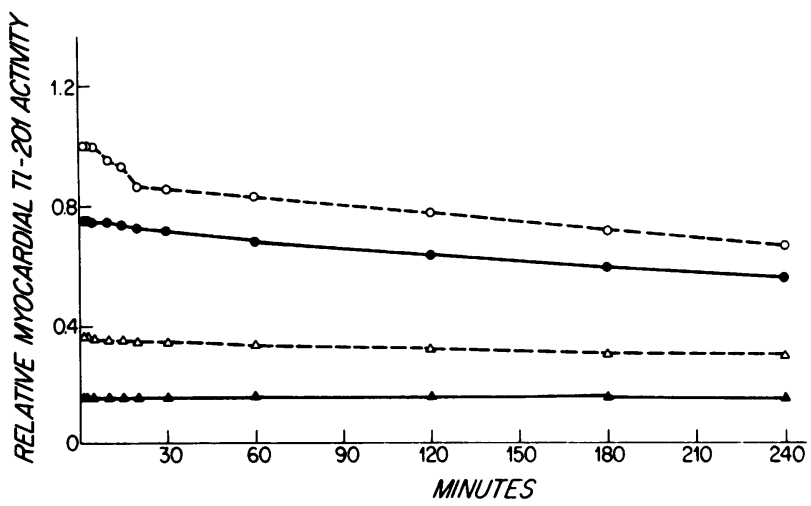

Figure 6 Relative myocardial Tl-201 activity over time for no stenosis zones and for stenosis zones of Groups 2, 3, and 4. Group $1(0)$, control group, no stenosis. Group $2(0)$, partial attenuation of hyperemia, no rest reduction group. Group $3(\Delta)$, complete attenuation of hyperemia, no rest reduction group. Group $4(\Delta)$, rest reduction in coronary flow group. to aid in the interpretation of Tl-201 studies. Such an analysis compares activity in one myocardial segment to that in another presumed to be normally perfused. Other quantitative computer techniques for determining the myocardial Tl-201 clearance rates for individual myocardial segments from serial images have been proposed as a means of detecting heterogeneity in additional patients, particularly those with balanced coronary lesions that reduce perfusion equally and those with constant attenuation from one area of the heart (4-7). Such an approach requires a knowledge of myocardial Tl-20l clearance rates in both normal and ischemic myocardium. Okada et al. (15) have previously determined normal and reduced flow myocardial $\mathrm{Tl}$ 201 clearances in a resting canine model. However, this model fails to detect coronary lesions that do not reduce resting blood flow. Exercise can detect coronary artery stenoses that do not reduce resting flow; however, an animal model for determining myocardial Tl201 clearance rates from the surface of the heart after exercise would be technically difficult to develop. The study of myocardial Tl-201 kinetics after dipyridamole infusion provides a readily available animal model and the possibility for detecting mild stenoses that attenuate the hyperemic response to vasodilation without decreasing flow at rest.

Hemodynamic response to intravenous dipyridamole. As the present study, previous studies using anesthetized open-chest dogs have shown a decrease in systemic arterial pressure, a decrease in coronary artery pressure distal to the stenosis, no significant change or a fall in heart rate, no significant change or a slight increase in cardiac output, and no significant

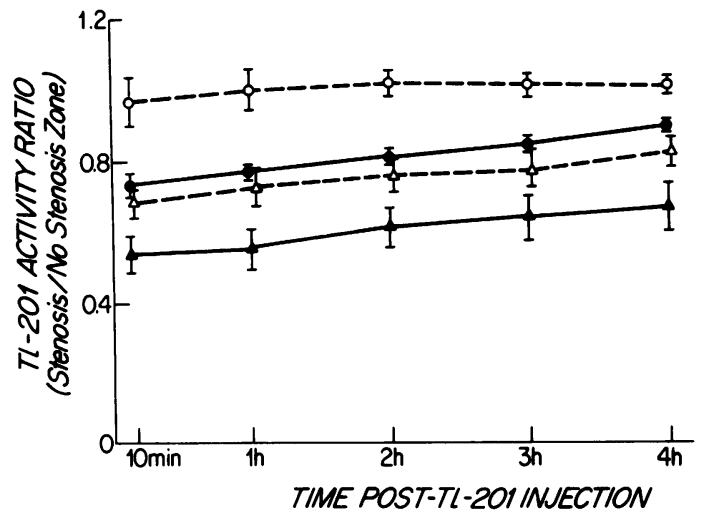

FIgURE 7 Tl-201 activity ratio (stenosis:no stenosis zone) over time for four groups of dogs. Group $1(\mathrm{O})$, control group, no stenosis $(P=$ NS). Group $2(\bullet)$, partial attenuation of hyperemia, no rest reduction group $(P<0.001)$. Group 3 $(\triangle)$, complete attenuation of hyperemia, no rest reduction group $(P<0.01)$. Group $4(\Delta)$, rest reduction in coronary flow group $(P<0.001)$. 
change in mean left atrial pressure after intravenous dipyridamole (16-20). Studies in intact, awake dogs have demonstrated no significant fall in systemic arterial pressure with intravenous dipyridamole (9). Studies in patients have demonstrated minor but significant increases in cardiac output and heart rate and decreases in mean systemic arterial pressure $(8$, 21-23).

Previous studies in normal dogs have demonstrated a $35-400 \%$ increase in coronary artery flow with intravenous dipyridamole, depending on the dose and method for calculating flow (16). These values are consistent with the $83 \%$ increase in coronary artery blood flow in control dogs in the present study. As observed in the dogs with mild stenoses in the present study, others have reported an increase in flow with dipyridamole, despite a fall in pressure distal to the stenosis $(19,24,25)$. This phenomenon has been explained by Gould et al. (8) to be due to energy or pressure losses resulting from viscous friction increasing in linear proportion to flow velocity as well as pressure losses due to flow separation increasing as a function of the square of velocity as flow velocity increases through a coronary stenosis. In the present study, the reduction in flow distal to a more severe stenosis (groups 3 and 4) after coronary vasodilatation is consistent with the reports of others $(8,17,19,26)$. Whether this decreased flow is due to a coronary steal phenomenon or to the decrease in systemic pressure in the face of a severe coronary stenosis is unclear.

The absence in the present study of any significant changes in systolic or diastolic wall thickness during dipyridamole is consistent with the reports of others (16). West and associates (16) reported no change in cardiac contractility secondary to dipyridamole.

Myocardial and blood kinetics of thallium-201 after dipyridamole. Okada et al. (27) have reported the normal Tl-201 myocardial clearance to be monoexponential with a decay constant $\lambda=0.0017 \mathrm{~min}^{-1}$ when Tl-201 is injected at rest. After dipyridamole, myocardial Tl-201 clearance is biexponential, clearing rapidly from normal myocardium $\left(\lambda_{1}=0.0611\right)$ over the first $20 \mathrm{~min}$, then at a slower rate similar to that after Tl-201 administration at rest. The initial rapid clearance is probably not related to persistent hyperemia per se, since increased flow has been shown to have no effect on myocardial Tl-201 clearance after Tl-201 loading $(28,29)$.

We have considered the possibility that the early rapid myocardial $\mathrm{Tl}-201$ clearance during the first 20 $\mathrm{min}$ is an artifact due to rapid clearance of Tl-201 from the blood perfusing the myocardium. The increased myocardial blood volume resulting from the vasodilation and hyperemia induced by dipyridamole increases the possibility of this artifact occurring.
However, two factors argue against such an artifact being the sole cause of the rapid myocardial Tl-201 clearance over the first $20 \mathrm{~min}$. First, although blood Tl-201 activity was high immediately after tracer injection, the activity then fell rapidly. 3 min after tracer injection blood Tl-201 activity was only $5 \%$ of myocardial activity (per gram). Second, previous studies of myocardial time-activity curves after Tl-20l administration at rest have not demonstrated a biexponential clearance (15).

As the coronary stenosis became increasingly severe, the present study demonstrated a progressive decrease in the 4-h myocardial Tl-201 clearance and in the second myocardial exponential decay constant $\lambda_{2}$, and a progressive increase in the time to peak Tl-201 activity. Okada et al. (15) have reported a decreased clearance rate and a prolongation of the time to peak Tl201 activity in a resting ischemic model. However, unlike the present study, the resting dog model was unable to differentiate normal myocardium from myocardium distal to coronary stenoses that did not reduce rest flow.

After dipyridamole, Tl-201 clearance from the blood was triexponential. The final blood exponential decay constant $\lambda_{3}$ was similar to the final normal myocardial exponential decay constant $\lambda_{2}$. Thus, beginning 20-45 min after administration, the rate of Tl-201 clearance from the myocardium appears to be related to the rate of Tl-201 clearance from the blood. Okada et al. (27) have demonstrated a similar relationship between myocardial and blood Tl-201 clearance rates beginning 20-30 min after injection when Tl-201 is administered to a normal dog at rest.

Time-course and mechanism of thallium-201 heterogeneity resolution after dipyridamole. With transient or persistent ischemia resting dog models, Tl-201 redistribution has been shown to be due to clearance of Tl-201 from normal myocardium and slow accumulation of Tl-201 in ischemic myocardium $(3,15$, 30 ). Using an occlusion model with release of the occlusion after Tl-201 administration, the initial defect has been demonstrated to rapidly resolve (15). However, even with persistent stenosis, significant Tl-201 redistribution after $4 \mathrm{~h}$ in areas with mild to moderate coronary flow reduction has been demonstrated (27). The present study demonstrates that the resolution of an initial Tl-201 heterogeneity after dipyridamole is probably the result of faster Tl-201 clearance from normal myocardium compared with myocardium distal to a stenosis. However, although the increases in stenosis:no stenosis zone Tl-201 ratio were significant for all three groups of dogs with stenoses, the magnitude of the changes was not great, and none of the groups demonstrated complete redistribution after $4 \mathrm{~h}$. Thus, it is not certain that these significant but small 
increases in the stenosis:no stenosis zone Tl-201 ratio could have been detected visually as Tl-201 redistribution on serial cardiac images, had imaging been performed. Furthermore, the lack of complete resolution of the Tl-201 heterogeneity after $4 \mathrm{~h}$ suggests that persistent defects on 2- or 4-h Tl-201 images may not always represent nonviable myocardium.

Clinical implications and conclusions. After dipyridamole, the clearance of $\mathrm{Tl}-201$ from normal myocardium is probably biexponential with a mean total clearance of $35 \%$ over $4 \mathrm{~h}$. The clearance rate decreases progressively distal to stenoses of increasing severity and differentiates between stenoses of graded hemodynamic severity. These results suggest that newly described quantitative techniques for evaluating serial clinical Tl-201 images may be applicable to determining myocardial Tl-201 clearance rates after dipyridamole in patients. Such clearance rate determinations may be helpful in determining the hemodynamic importance of a coronary stenosis.

\section{ACKNOWLEDGMENTS}

The authors wish to thank Betty LaMarca and Katherine Hogan for their secretarial assistance, John Newell (Data Management Project of the Ischemic Heart Disease-Specialized Center on Research at the Massachusetts General Hospital) for his statistical assistance, and Dan Harris for his technical assistance.

This research was supported, in part, by U. S. Public Health Service grant HL-21751-04.

\section{REFERENCES}

1. Okada, R. D., C. A. Boucher, H. W. Strauss, and G. M. Pohost. 1980. Exercise radionuclide imaging approaches to coronary artery disease. Am. J. Cardiol. 46: 11881204

2. Pohost, G. M., L. M. Zir, R. H. Moore, K. A. McKusick, T. E. Guiney, and G. A. Beller. 1977. Differentiation of transiently ischemic from infarcted myocardium by serial imaging after a single dose of thallium-201. Circulation. 55: 294-302.

3. Pohost, G. M., R. D. Okada, D. D. O'Keefe, H. Gewirtz, G. Beller, H. W. Strauss, J. Leppo, and W. M. Daggett. 1981. Thallium redistribution in dogs with severe coronary artery stenosis of fixed caliber. Circ. Res. 48: 439446.

4. Berger, B. C., D. D. Watson, G. J. Taylor, L. R. Burwell, R. P. Martin, and G. A. Beller. 1980. Effect of coronary collateral circulation on regional myocardial perfusion assessed with quantitative thallium-201 scintigraphy. Am. J. Cardiol. 46: 365-370.

5. Watson, D. D., N. P. Campbell, B. C. Berger, and G. A. Beller. 1980. Quantitation of Tl-201 myocardial distribution and washout: normal standards for graded exercise studies. Am. J. Cardiol. 45: 480. (Abstr.)

6. Gewirtz, H., M. J. Sullivan, D. R. Shearer, D. Delude, A. K. Fitzgibbons, and A. S. Most. 1979. Time activity analysis of normal zones in thallium scans of patients with CAD. J. Nucl. Med. 20: 649. (Abstr.)
7. Garcia, E., J. Maddahi, D. S. Berman, A. Waxman, and H. J. C. Swan. 1980. A comprehensive method for spacetime quantitation of sequential thallium-201 myocardial scintigrams. Circulation. 62(Suppl. 3): 75. (Abstr.)

8. Gould, K. L., R. J. Westcott, P. C. Albro, and G. W. Hamilton. 1978. Noninvasive assessment of coronary stenoses by myocardial imaging during pharmacologic coronary vasodilatation. II. Clinical methodology and feasibility. Am. J. Cardiol. 41: 279-287.

9. Gould, K. L. 1978. Noninvasive assessment of coronary stenoses by myocardial perfusion imaging during pharmacologic coronary vasodilatation. I. Physiologic basis and experimental validation. Am. J. Cardiol. 41: 267278.

10. Albro, P. C., K. L. Gould, R. J. Westcott, G. W. Hamilton, J. L. Ritchie, and D. L. Williams. 1978. Noninvasive assessment of coronary stenoses by myocardial imaging during pharmacologic coronary vasodilatation. III. Clinical trial. Am. J. Cardiol. 42: 751-760.

11. Leppo, J., C. A. Boucher, R. D. Okada, H. W. Strauss, and G. M. Pohost. Utility of serial thallium imaging following dipyridamole. Am. J. Cardiol. In press.

12. Jacobs, M. L., R. D. Okada, H. W. Strauss, B. N. Fowler, J. B. Newell, D. O'Keefe, W. M. Daggett, and G. M. Pohost. 1980. Continuous monitoring of regional myocardial radiotracer kinetics in laboratory animals. Am. J. Cardiol. 45: 464. (Abstr.)

13. Gewirtz, H., G. J. Grotte, H. W. Strauss, D. D. O'Keefe, C. W. Akins, W. M. Daggett, and G. M. Pohost. 1979. The influence of left ventricular volume and wall motion on myocardial images. Circulation. 59: 1172-1177.

14. Domenech, R. J., J. I. E. Hoffman, M. I. M. Noble, K. B. Saunders, J. R. Henson, and S. Subijanto. 1969. Total and regional coronary blood flow measured by radioactive microspheres in conscious and anesthetized dogs. Circ. Res. 25: 581-596.

15. Okada, R. D., J. A. Leppo, H. W. Strauss, W. M. Daggett, C. A. Boucher, M. L. Jacobs, J. B. Newell, and G. M. Pohost. 1980. Mechanisms for the disappearance of Tl201 defects at rest over time. Am. J. Cardiol. 45: 479. (Abstr.)

16. West, J. W., S. Bellet, U. C. Manzoli, and O. F. Müller. 1962. Effects of Persantin (RA8), a new coronary vasodilator, on coronary blood flow and cardiac dynamics in the dog. Circ. Res. 10: 35-44.

17. Fam, W. M., and M. McGregor. 1964. Effects of coronary vasodilator drugs on retrograde flow in areas of chronic myocardial ischemia. Circ. Res. 15: 355-365.

18. Becker, L. C. 1976. Effect of nitroglycerin and dipyridamole on regional left ventricular blood flow during coronary artery occlusion. J. Clin. Invest. 58: 12871296.

19. Flameng, W., B. Wüsten, and W. Schaper. 1974. On the distribution of myocardial flow. II. Effects of arterial stenosis and vasodilation. Basic Res. Cardiol. 69: 435446.

20. Elliot, E. C. 1961. The effect of persantine on coronary flow and cardiac dynamics. Can. Med. Assoc. J. 85: 469476.

21. Tauchert, M., K. Kochsiek, and H. W. Heiss. 1972. Measurement of coronary blood flow in man by the argon method. In Myocardial Blood Flow in Man. A. Maseri, editor. Minerva Medica, Torino. 139-144.

22. Arroti, J., R. M. Gunnar, J. Ward, and H. S. Loeb. 1980. Comparative effects of intravenous dipyridamole and sublingual nitroglycerin on coronary hemodynamics and 
myocardial metabolism at rest and during atrial pacing in patients with coronary artery disease. Clin. Cardiol. 3: 365-370.

23. Sorensen, S., B. Groves, and T. Chaudhuri. 1980. Regional myocardial blood flow and hemodynamics in man after intravenous dipyridamole. Circulation. 62(Suppl. 3): 9. (Abstr.)

24. Young, D. F., and F. Y. Tsai. 1973. Flow characteristics in models of arterial stenosis. I. Steady flow. J. Biomech. 6: $395-410$.

25. Gould, K. L., K. Lipscomb, and C. Calvert. 1975. Compensatory changes of the distal coronary vascular bed during progressive coronary constriction. Circulation. 51: 1085-1095.

26. Wilcken, D. E. L., H. J. Paoloni, and E. Eikens. 1971. Evidence for intravenous dipyridamole producing a cor- onary steal effect in the ischemic myocardium. Aust. N. Z. J. Med. 1: 8-14.

27. Okada, R. D., M. L. Jacobs, J. B. Newell, H. W. Strauss, W. M. Daggett, D. D. O'Keefe and G. M. Pohost. 1979. Thallium-201 kinetics in nonischemic canine myocardium. Circulation. 60(Suppl. 2): 172. (Abstr.)

28. Leppo, J. A., R. D. Okada, J. L. Guerrero, H. W. Strauss, and G. W. Pohost. 1980. The relationship of coronary flow to Tl-201 redistribution. Am. J. Cardiol. 45: 480. (Abstr.)

29. L'Abbate, A., A. Biagini, C. Michelassi, and A. Maseri. 1979. Myocardial kinetics of thallium and potassium in man. Circulation. 60: 776-785.

30. Beller, G. A., D. D. Watson, P. Ackell, G. M. Pohost. 1980. Time course of thallium-201 redistribution after transient myocardial ischemia. Circulation. 61: 791797. 